\title{
Beyond Checklist Approaches to Ethics in Design
}

Richmond Y. Wong

University of California, Berkeley

ryw9@berkeley.edu

Jake Metcalf

Data \& Society

jake.metcalf@datasociety.net

\section{Karen Boyd}

University of Maryland College Park

klboyd@umd.edu

\section{Katie Shilton}

University of Maryland College Park

kshilton@umd.edu

\section{ABSTRACT}

Recent public discussions about technologies and social values have called for greater consideration of ethics during technology development and deployment, leading many organizations to create and promote compliance- or checklist-oriented toolkits and frameworks to address values and ethical issues. However, surfacing discussion and consideration of ethics in broader, more open-ended ways during the design process may help surface unique needs, social corner cases, or new or different understandings of values and ethics.

This one-day workshop will convene CSCW researchers and practitioners to propose and consider new interventions and approaches to ethics in design that go beyond formal checklist- and compliance-oriented approaches. CSCW's rich set of methods when investigating values and ethics provides a starting point for developing new approaches and interventions. These may potentially include design activities, games and roleplaying, critical making, changes to work practice and organizational structure, or conducting empirical research. Our goal is to explore multiple and alternative forms of values and ethics interventions, rather than coming to a particular "best" approach. This workshop aims to map out a space of interventions for values and ethics, propose new approaches and interventions, and craft an agenda for experimenting with and evaluating new interventions.

\section{(c) (9)}

This work is licensed under a Creative Commons Attribution International 4.0 License.

CSCW '20 Companion, October 17-21, 2020, Virtual Event, USA

( 2020 Copyright is held by the owner/author(s).

ACM ISBN 978-1-4503-8059-1/20/10.

https://doi.org/10.1145/3406865.3418590 


\section{KEYWORDS}

ethics, values, design, interventions, methods, practices, values in design

\section{WORKSHOP THEME}

Recent public and academic discussions about the intersection of technologies and social values call for greater consideration of ethics in technology development and deployment. The desire to see technology companies address social values has been surfaced in new ways, in part due to regulatory forces (e.g., the California Consumer Privacy Act and the EU General Data Protection Regulation), public scandals like data breaches or systems that cause harm to marginalized communities, as well as technology worker actions such as walkouts and letter writing. These efforts view practices related to technology production as sites of intervention to promote, protect, or embed ethics and social values. The range of social values at stake range from concerns about privacy and fairness in data collection and use, to the potential harms of algorithmic categorization and decision making, to the potential for platforms to enable action based on racial biases or spread misinformation, to manipulation of users' behavior using data or designed dark patterns, to corporate contracts with militaries and governments perpetuating harms, and the need for greater diversity and inclusion within technology companies' workforces (e.g., $[10,13,16,20,22,24])$. The location of the ethics problem varies across these concerns, for instance some being concerned about the technical products themselves, some focusing on the ways in which technologies are used, and others focusing on the people and organizations creating technical artifacts.

Interdisciplinary research under the rubric of "values in design" has long been interested in how technological artifacts and the practices of production promote or embed social values, ethics, and politics, and how technology designers' practices and beliefs affect these artifacts [1,5,14,21]. Values in Design research in CSCW and adjacent fields has sought to analyze how social values are implicated in practices of technology design, creation, maintenance, and repair $[8,9,15,20,22]$. Parallel research from the human computer interaction $(\mathrm{HCl})$ and design research communities has developed a range of design approaches to develop technical systems in ways that are cognizant of values and ethics and center their promotion as a core goal of design (e.g., [3,4,7]).

Simultaneously to this work in $\mathrm{HCl}$ and $\mathrm{CSCW}$, industry approaches to intervening in values and ethical issues in practice have largely adopted compliance- or checklist-oriented approaches. This includes creating legal compliance programs for values articulated in laws and regulations (such as privacy ${ }^{1}$ ) or checklist-based toolkits, such as the Ethical OS toolkit, ${ }^{2}$ Ethics \& AI toolkit, ${ }^{3}$ IBM's AI Fairness 360 toolkit, ${ }^{4}$ and the Digital Impact toolkit, ${ }^{5}$ among many in circulation. ${ }^{6}$ These toolkits and approaches may present practitioners with a set of guidelines they should follow, sets of checklists, or a set of diagnostic questions to ask themselves. While useful tools, these approaches tend to predefine what values or ethics mean; there is some set of exogenous values or ethics requirements that the tool helps a practitioner meet.

1 https://iapp.org/resources/article/developing-a-privacy-compliance-program/

2 https://ethicalos.org/

${ }^{3}$ https://ethicstoolkit.ai/

${ }^{4}$ https://developer.ibm.com/technologies/artificial-intelligence/projects/ai-fairness-360/

${ }^{5} \mathrm{https} / / /$ digitalimpact.io/toolkit/

${ }^{6}$ E.g., https://www.intel.com/content/www/us/en/artificial-intelligence/posts/ai-ethics-toolkits.htm 
Several also frame issues of ethics and values as risk-management problems. However, surfacing discussion and consideration of ethics and values in broader, more open-ended ways during the design process may help surface unique needs, social corner cases, or new or different understandings of values and ethics [11].

\section{WORKSHOP GOALS \& OUTCOMES}

This workshop will convene CSCW researchers and practitioners working across a wide array of domains to propose and consider new interventions and approaches to ethics in design that go beyond formal checklist- and compliance-oriented approaches. CSCW's rich set of qualitative, quantitative, and design-based methods when investigating values and ethics [20] provides a starting point for thinking about approaches and interventions for ethics and values in design that go beyond compliance- and checklist- oriented approaches. These may include new design-based activities (e.g., [2,22]), games and roleplaying (e.g., [18]), critical making (e.g., [17]), considerations of and changes to organizational structure and work practice (e.g., $[8,12,19])$, or conducting empirical research on ethics and values. We take the conceptual multiplicity surrounding ethics as an opportunity to convene researchers and practitioners from different disciplines to map out a broader space of approaches to values and ethics in design, exploring the complimentary advantages of alternative modes of intervention. Thus our goal is to explore multiple and alternative forms of values and ethics interventions, rather than coming to a particular "correct" or "best" approach.

This workshop contributes to values and ethics in design research by (1) mapping out a space of interventions for values and ethics, (2) proposing new approaches and interventions, and (3) crafting an agenda for experimenting with and evaluating design interventions.

\section{WORKSHOP STRUCTURE}

The workshop will take place synchronously over the course of one day, using a remote video conferencing platform that allows for breakout groups (such as Zoom). We will both engage in intervention activities developed by the organizers (including a collaborative design fiction activity and the Privacy by Design game [18,23]), as well as any additional activities submitted by workshop participants. Shared digital documents (such as a shared Google Document) will be used to help participants share and record ideas with one another. Several interactive activities may ask participants to use shared digital materials such as filling out a shared Google Slide deck, or to use basic materials from their own environment (such as pen and paper). We will provide any additional materials such as links to online games or activities. We can support up to 25 participants in this workshop. Before the workshop, we will also provide an opportunity for participants to notify us of accessibility considerations. We will provide materials to all participants in advance of the workshop itself, such as participant position papers and activity instructions, so that participants can familiarize themselves with the materials before the workshop. 


\section{Table 1: Tentative Workshop Schedule}

\begin{tabular}{ll}
\hline Time (CDT) & Activity \\
\hline 9:00-9:30am & $\begin{array}{l}\text { Welcome: Introductions, Framing, } \\
\text { and Goals }\end{array}$ \\
9:30-10:30am & $\begin{array}{l}\text { Concept Mapping Group Exercise } \\
\text { \& Discussion }\end{array}$ \\
& $\begin{array}{l}\text { 30-minute break } \\
\text { 10:30-11:00am }\end{array}$ \\
11:00-12:30pm & Breakout Activity 1 \& Report-back \\
12:30-1:30pm & 1-hour break \\
1:30-3:00pm & Breakout Activity 2 \& Report-back \\
3:00-3:30pm & 30-minute break \\
3:30-4:00pm & $\begin{array}{l}\text { Revisiting the Concept Map } \\
\text { 4:00-4:30pm }\end{array}$ \\
& $\begin{array}{l}\text { Closing Discussion: Reflections } \\
\text { and Next Steps }\end{array}$ \\
\hline
\end{tabular}

\section{Workshop Schedule}

We anticipate starting the workshop at 9am U.S. central time, but may shift the start time based on the geographic location of participants. See Table 1 for details of the tentative workshop schedule. The exact schedule may be adjusted closer to the workshop.

\section{Activity Descriptions}

Concept Mapping - In order to organize the discussion and document the workshop's activity, the day will start with a group creation of a digital concept map using a shared Google Slide deck, or similar platform, which will be updated throughout the day. In the morning, as participants introduce themselves and their perspectives on ethics in design, we will ask them to record their perspectives on the concept map. The map will be updated as methods, practices, terms, projects, and activities are discussed throughout the day. At the end of the day, we will revisit the concept map to reflect on the design space of interventions for ethics in design, and identify areas for future work.

Breakout Activity 1 - In the first breakout activity session, small groups of participants will try using a contrasting range of existing values and ethics tools, including the practitioner toolkits mentioned earlier, as well as toolkits and interventions developed in CSCW and adjacent research, such as the Privacy by Design game [18], collaborative design fiction activities [23], and Value Sensitive Design envisioning cards [6]. This break-out session will help us map the space of existing tools, identify their strengths and weaknesses, and understand how they frame ethics and values problems in different ways.

Breakout Activity 2 - In the second breakout activity session, participants will use the design space mapped out by the earlier activities, and their own perspectives and experiences to ideate and iterate on new forms of interventions for addressing ethics and values in design. We will encourage participants to think about a broad range of social and technical interventions such as technical toolkits, design activities, advocacy guides, community and worker organizing strategies, and other ideas that emerge from the workshop.

\section{Website}

The website for the workshop is located at: http://EthicsInDesignWorkshop.wordpress.com. It will host the call for participation, resources and background, details on the rationale and goals of the event, desired outcomes, and information about the organizers. Closer to the conference, it will also host the accepted position papers and relevant logistical information for participants. Following the workshop, the site will be updated to include the outcomes of the day's work. 


\section{Key Dates}

- July 31, 2020: Website and call for participation published

- August 31, 2020: Initial deadline for position papers (submissions will be accepted until September 20, 2020 on a rolling basis)

- September 20, 2020: Notification of acceptance to participants

- October 3, 2020: Camera-ready position papers due

- October 17/18, 2020: Workshop

\section{ORGANIZERS}

Richmond Wong studies how designers and UX professionals attend to values and ethical issues in their professional practices, and how new design methods can aid in this work. He is a Postdoctoral Scholar at the Center for Long Term Cybersecurity at the University of California Berkeley, where he draws on approaches from design research, critical and speculative design, and science \& technology studies.

Karen Boyd is a PhD candidate at the University of Maryland, College Park. She studies values in practice and ethical sensitivity in technology development, especially machine learning development.

Jake Metcalf, $\mathrm{PhD}$, is a researcher at Data \& Society, where he is a member of the $\mathrm{Al}$ on the Ground Initiative, and works on an NSF-funded multisite project, Pervasive Data Ethics for Computational Research (PERVADE). For this project, he studies how data ethics practices are emerging in environments that have not previously grappled with research ethics, such as industry, IRBs, and civil society organizations. His recent work has focused on the new organizational roles that have developed around Al ethics in tech companies.

Katie Shilton is an associate professor in the College of Information Studies at the University of Maryland, College Park. Her research explores ethics and policy for the design of information technologies. She is the PI of the PERVADE project, a multi-campus collaboration focused on big data research ethics. Other projects include developing privacy-sensitive search for email collections; analyzing ethical cultures in computer security research; and building tools to facilitate ethics discussions in mobile application development.

\section{CALL FOR PARTICIPATION}

This one-day workshop aims to convene CSCW researchers working in a wide range of domains including: values in design, design research, social justice, work studies, machine learning, and others to propose and consider new interventions and approaches to ethics in technology design that go beyond formal checklist- and compliance-oriented approaches.

To apply, please send a position paper (up to 4 pages, not including references) to cscw.ethicsindesign@gmail.com before Sept. 20, 2020 (papers submitted before Aug. 31, 2020 will be given earlier consideration). Position papers should be the ACM Extended Abstract format. Position papers may take the form of:

- Practice-based or methods pieces that explore approaches to addressing ethics in design;

- Proposed activities or toolkits;

- Ideas for interventions, games, role-playing, theater, or art focused on technology ethics;

- Original or proposed research related to ethics in design, or ethics in organizational and work practice;

- Pictorials, design fictions, or other creative pieces that deal with ethics in design;

- Additional formats, including essays that review historical approaches to ethics in design, theory-building pieces, etc. Please feel free to email organizers with questions or ideas. 
The workshop will take place as part of the ACM Conference on Computer-Supported Cooperative Work and Social Computing (CSCW), occurring virtually in October 2020. The workshop will take place using Zoom or a similar remote video conference platform. At least one author of each accepted position paper will be required to register for the workshop. More information about this workshop can be found at: http://EthicsInDesignWorkshop.wordpress.com. Please email any questions to: cscw.ethicsindesign@gmail.com.

\section{REFERENCES}

[1] Madeleine Akrich. 1992. The De-Scription of Technical Objects. In Shaping Technology Building Society: Studies in Sociotechnical Change, Wiebe Bijker and John Law (eds.). MIT Press, 205-224.

[2] Stephanie Ballard, Karen M. Chappell, and Kristen Kennedy. 2019. Judgment Call the Game: Using value sensitive design and design fiction to surface ethical concerns related to technology. In Proceedings of the 2019 on Designing Interactive Systems Conference - DIS '19, 421-433. https://doi.org/10.1145/3322276.3323697

[3] Lynn Dombrowski, Ellie Harmon, and Sarah Fox. 2016. Social Justice-Oriented Interaction Design. In Proceedings of the 2016 ACM Conference on Designing Interactive Systems (DIS '16), 656-671. https://doi.org/10.1145/2901790.2901861

[4] Paul Dourish, Janet Finlay, Phoebe Sengers, and Peter Wright. 2004. Reflective HCl: Towards a Critical Technical Practice. CHI'04 Extended Abstracts on Human Factors in Computing Systems: 1727-1728. https://doi.org/10.1145/985921.986203

[5] Mary Flanagan, Daniel C. Howe, and Helen Nissenbaum. 2008. Embodying values in technology: Theory and practice. In Information technology and Moral Philosophy, Jeroen Van Den Hoven and John (Charles Sa Weckert (eds.). Cambridge University Press, New York, 322-353. Retrieved June 15, 2014 from http://medcontent.metapress.com/index/A65RM03P4874243N.pdf

[6] Batya Friedman and David Hendry. 2012. The envisioning cards: a toolkit for catalyzing humanistic and technical imaginations. In Proceedings of the 2012 ACM annual conference on Human Factors in Computing Systems (CHI '12), 11451148. https://doi.org/10.1145/2207676.2208562

[7] Batya Friedman, Peter H. Kahn, and Alan Borning. 2008. Value Sensitive Design and Information Systems. In The Handbook of Information and Computer Ethics, Kenneth Einar Himma and Herman T. Tavani (eds.). John Wiley \& Sons, Inc., 69-101.

[8] Colin M. Gray and Shruthi Sai Chivukula. 2019. Ethical Mediation in UX Practice. In Proceedings of the $2019 \mathrm{CH}$ Conference on Human Factors in Computing Systems - CHI '19, 1-11. https://doi.org/10.1145/3290605.3300408

[9] Lara Houston, Steven J Jackson, Daniela K Rosner, Syed Ishtiaque Ahmed, Meg Young, and Laewoo Kang. 2016. Values in Repair. In Proceedings of the 2016 CHI Conference on Human Factors in Computing Systems - CHI '16, 1403-1414. https://doi.org/10.1145/2858036.2858470

[10] Steven J. Jackson, Tarleton Gillespie, and Sandy Payette. 2014. The policy knot. In Proceedings of the 17th ACM conference on Computer supported cooperative work \& social computing - CSCW '14, 588-602. https://doi.org/10.1145/2531602.2531674

[11] Nassim JafariNaimi, Lisa Nathan, and Ian Hargraves. 2015. Values as Hypotheses: Design, Inquiry, and the Service of Values. Design Issues 31, 4: 91-104. https://doi.org/10.1162/DESI_a_00354

[12] Jacob Metcalf, Emanuel Moss, and Danah Boyd. 2019. Owning ethics: Corporate logics, Silicon Valley, and the institutionalization of ethics. Social Research 86, 2: 449-476.

[13] Michael Muller. 2014. Whose Values? Whose Design? CSCW Workshop on Co-creating \& Identity-making in CSCW. Retrieved from http://ethicsworkshopcscw2014.files.wordpress.com/2013/10/muller-whose-values.pdf

[14] Helen Nissenbaum. 2001. How computer systems embody values. Computer 34, 3: 120-119. https://doi.org/10.1109/2.910905

[15] Samir Passi and Steven J Jackson. 2018. Trust in Data Science: Collaboration, Translation, and Accountability in Corporate Data Science Projects. Proceedings of the ACM on Human-Computer Interaction 2, CSCW: 1-28. https://doi.org/10.1145/3274405 
[16] Pablo Alejandro Quinones, Stephanie D. Teasley, and Steven Lonn. 2013. Appropriation by unanticipated users: Looking beyond design intent and expected use. Proceedings of the ACM Conference on Computer Supported Cooperative Work, CSCW: 1515-1526. https://doi.org/10.1145/2441776.2441949

[17] Matt Ratto. 2011. Critical making: Conceptual and material studies in technology and social life. Information Society 27, 4: 252-260. https://doi.org/10.1080/01972243.2011.583819

[18] K. Shilton, D. Heidenblad, A. Porter, S. Winter, and M. Kendig. (In press) Role-Playing Computer Ethics: Designing and Evaluating the Privacy by Design Simulation. Science and Engineering Ethics.

[19] Katie Shilton. 2013. Values Levers: Building Ethics into Design. Science, Technology, \& Human Values 38, 3: 374-397. https://doi.org/10.1177/0162243912436985

[20] Katie Shilton, Jes A. Koepfler, and Kenneth R. Fleischmann. 2014. How to see values in social computing: Methods for Studying Values Dimensions. In Proceedings of the 17th ACM Conference on Computer Supported Cooperative Work \& Social Computing (CSCW '14), 426-435. https://doi.org/10.1145/2531602.2531625

[21] Langdon Winner. 1980. Do Artifacts Have Politics? Daedalus 109, 1: 121-136.

[22] Richmond Y. Wong, Deirdre K Mulligan, Ellen Van Wyk, James Pierce, and John Chuang. 2017. Eliciting Values Reflections by Engaging Privacy Futures Using Design Workbooks. Proceedings of the ACM on Human Computer Interaction 1, CSCW. https://doi.org/10.1145/3134746

[23] Richmond Y Wong and Nick Merrill. 2019. Engaging Speculative Practices to Probe Values \& Ethics in Sociotechnical Systems. Retrieved from https://ischools.org/resources/Documents/iconf 2019/iConf2019_SIE_Values-and-Ethics-inSociotechnical-Systems.pdf

[24] Haiyi Zhu, Bowen Yu, Aaron Halfaker, and Loren Terveen. 2018. Value-Sensitive Algorithm Design: Method, Case Study, and Lessons. Proceedings of the ACM on Human-Computer Interaction 2, CSCW: 1-23. https://doi.org/10.1145/3274463 